ON THE RECORD

“Nobody cares about contaminating the

Moon. It's like

New Jersey."

Astrobiologist Chris McKay explains whyearly exploration missions will test technologies on the Moon, rather than on Mars.

\section{cCl'm kind of} disappointed, but I guess I did OK."

Fifteen-year-old Gaurav Rajav fails to breaka North American record for reciting the digits of pi. He masters 8,784 digits.

Sources: News@nature; AP

\section{SCORECARD}

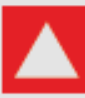

Stuffed animals The yeticrab, recently discovered in the South

Pacific deeps, is honoured with itsown sewing pattern - letting you recreate it as a plush toy.

$\sqrt{7}$ Chopsticks The Chinese government adds a $5 \%$ tax to disposable wooden chopsticks, in an attempt to slow deforestation.

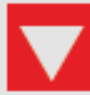
Organs Europe restricts the building of pipe organs, saying the instruments violate a European Union directive to limit the amount of lead contained in products that work on electricity.

\section{NUMBER CRUNCH}

Nobel-prizewinning physicist Carl Wieman announced last week that he is leaving the University of Colorado, where he has worked for 22 years, and joining the University of British Columbia. Why?

$\$ \mathbf{2 2 7}, \mathbf{0 0 0}$ is Wieman's base salary at Colorado.

$\$ 3$ million is the amount paid to Colorado's football coach after he was fired following several scandal-laden seasons.

$\$ 10$ million is the amount the Canadian university has promised Wieman forhis science-education efforts. Wieman is taking a salary cut to go there, but says that at least British Columbia values academics as highly as athletes.

\title{
Scans suggest IQ scores reflect brain structure
}

Researchers say that a remarkable data set on the developing brain adds to the idea that IQ is a meaningful concept in neuroscience. The study, which is published on page 676 of this issue, suggests that performance in IQ tests is associated with changes in the brain during adolescence.

Claims that IQ is a valid measure of intelligence tend to attract angry responses, in part because of studies that have attempted to link group differences in IQ with race. In their 1994 book The Bell Curve, political scientist Charles Murray and psychologist Richard Herrnstein argued that the lower-income status of some US ethnic minorities was linked to below-average IQ scores among those groups. These were in turn attributed to mainly genetic factors.

Before that, Harvard University entomologist Edward Wilson provoked outrage with work that proposed evolutionary explanations for human behaviour and individual differences in intelligence; critics called the work racist. And this month, the journal Intelligence printed an editorial note defending its policy regarding the publication of controversial papers. The note comes after a study linking IQ and skin colour (D. I. Templer and H. Arikawa Intelligence 34, 121-139; 2006), published online last November, prompted a string of complaints from scientists.

Yet researchers studying IQ say the social climate is becoming more receptive to such studies, in part because it is now widely agreed that cognitive abilities are shaped by environmental factors as well as genetic ones.
The latest result, from a team led by Philip Shaw at the National Institute of Mental Health in Bethesda, Maryland, adds to the debate by linking IQ with changes in the brain over time, rather than fixed attributes such as brain size. "It's not that brainy children have more grey matter," says Shaw. "The story of intelligence is in the trajectory of brain development."

Shaw's team tracked a group of more than 300 children as they aged from 6 to 19 , running them through a series of cognitive tests - IQ is determined by combining scores from tests of a range of verbal and non-verbal abilities. The team also measured the size of brain structures using magnetic resonance imaging at roughly two-year intervals: more than half the children had at least two scans, and around a third were scanned three or more times.

When the researchers split the children into three groups according to their initial IQ scores, they noticed a characteristic pattern of changes in the brains of the group with the highest scores. The thickness of the cortex - the outer layer of
IMAGE UNAVAILABLE FOR COPYRIGHT REASONS

\section{Italians put science chief on the spot}

Italian scientists are pressuring the president of the National Research Council (CNR) to justify his plans for reforming the agency - and to come clean about his academic background.

Up to 1,000 scientists from across Italy are expected to gather in Rome on 30 March to demonstrate over their unhappiness with the CNR's management team - installed by Prime Minister Silvio Berlusconi's government two years ago. The council runs almost 100 of Italy's research institutes.
"We are particularly concerned about the administrative council's plans to restructure the CNR's institutes, merging them into 67 entities - based only on bureaucratic not scientific considerations," says Rino Falcone of the CNR Institute of Cognitive Sciences and Technology in Rome.

Falcone helped to organize the march following a report in Nature earlier this month that described researchers' increasingly public dissatisfaction with the government's science policy (see 
the brain that controls high-level functions such as memory - started off thinner than that of the other groups, but rapidly gained depth until it was thicker than normal during the early teens. All three groups converged, with the children having cortexes of roughly equal thickness by age 19 . The strongest effect was seen in the prefrontal cortex, which controls planning and reasoning.

"My first impression was "wow, this is amazing,", says Jeremy Gray, a psychologist at Yale University in New Haven, Connecticut. He notes that it is difficult to persuade children and parents to return for scans over a long period of time, so imaging studies are usually limited to tens, rather than hundreds, of subjects.

Shaw's study raises questions that could prompt further research. His team did not look

\section{IMAGE UNAVAILABLE FOR COPYRIGHT REASONS}

at what could be causing the changes in cortical thickness, for example; the group points out that several mechanisms - including the formation and elimination of connections between brain cells - could be responsible. Also unknown is how genetic and environmental factors contribute to the change.

The study is likely to prompt discussion of the possible social applications of such results, but these are limited. The trend identified by Shaw was significant when results from all the subjects were combined, but would probably be too small to predict how an individual child is likely to fare in school, for example.

There are also likely to be queries about whether the research should have been conducted in the first place. IQ is a good predictor of performance at school and in the workplace. For some neuroscientists, this makes the physiological factors that contribute to IQ worth studying, in order to probe how intelligence works. ${ }^{\alpha}$ There's good evidence from functional imaging studies that very demanding tasks activate the prefrontal cortex, and that activity correlates with $\mathrm{IQ}^{\text {" }}$ says Shaw. "We're getting at some common processing resource."

Gray also points out that metrics related to IQ can help predict speed of recovery from stroke, so studying them could lead to new therapies. But for many others, the concept of linking IQ and intellect remains socially dangerous and scientifically dubious. Steven Rose, a neuroscientist at the Open University in Milton Keynes, UK, says performance on cognitive tasks depends on a large range of factors, from emotive state to recall ability, and that the "IQ approach ignores all of these. ${ }^{m}$. He adds that even as a predictor of ability in school it has traditionally been put to negative ends - to weed out, rather than help, less able children. "We shouldn't go back to measures developed in the $1900 \mathrm{~s}$," he says.

Jim Giles
Nature 440, 264-265; 2006).

The Nature article also reported that CNR president Fabio Pistella had supported his candidature for the presidency with a $\mathrm{CV}$ claiming 150 publications. Only three have been identified by Thomson ISI searches, but Pistella retorted that his role required only "management skills". On 21 March, 39 of Italy's most highly cited scientists sent an open letter to Pistella daiming that this response to the "serious" charge "did not fit the dignity" of his function as CNR president.

Theletter also accuses Pistella of having helped cause the decline of Italy's energy and environment agency - which he headed before joining the CNR. It asks him to clarify the criteria for his proposed restructuring of the CNR so as to prevent it from suffering the same fate as the energy agency.

Finally, the letter challenges Pistella to reveal the details of his scientific publications. "We believe this is the only way to restore a relationship of trust and dialogue with the entire national and international scientific community, it says. Pistella has responded with a promise to publish his full reference list on the CNR website. But he had not done so by the time Nature went to press.

Alison Abbott 